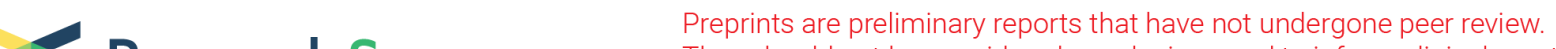 Research Square
Thr ef should not be considered conclusive, used to inform clinical practice,
on the media as validated information.
}

\section{The human arthritic hip joint is a source of mesenchymal progenitor cells (MPCs) with extensive multipotent differentiation potential}

\section{Mike Wagenbrenner}

Orthopädische Klinik König-Ludwig-Haus

\section{Tizian Heinz}

Orthopädische Klinik König-Ludwig-Haus

\section{Konstantin Horas}

Orthopädische Klinik König-Ludwig-Haus

\section{Axel Jakuscheit}

Orthopädische Klinik König-Ludwig-Haus

\section{Joerg Arnholdt}

Orthopädische Klinik König-Ludwig-Haus

\section{Marietta Herrmann}

Research Group Tissue Regeneration of the University Clinics Wuerzburg

\section{Maximilian Rudert}

Orthopädische Klinik König-Ludwig-Haus

\section{Boris Holzapfel}

Orthopädische Klinik König-Ludwig-Haus

\section{Andre Steinert}

Rhoen-Klinikum Campus Bad Neustadt

Manuel Weißenberger ( $\Delta$ m-weissenberger.klh@uni-wuerzburg.de )

Orthopadische Klinik Konig-Ludwig-Haus https://orcid.org/0000-0003-3551-3204

\section{Research article}

Keywords: Hip joint, osteoarthritis, MPCs, cartilage regeneration, tissue engineering, ligamentum capitis femoris, joint capsule

Posted Date: March 17th, 2020

DOI: https://doi.org/10.21203/rs.3.rs-17537/v1

License: (c) (1) This work is licensed under a Creative Commons Attribution 4.0 International License. Read Full License 
Version of Record: A version of this preprint was published at BMC Musculoskeletal Disorders on May 13th, 2020. See the published version at https://doi.org/10.1186/s12891-020-03340-z. 


\section{Abstract}

Background: While multiple in vitro studies examined mesenchymal progenitor cells (MPCs) derived from bone marrow or hyaline cartilage, there is little to no data about the presence of MPCs in the joint capsule or the ligamentum capitis femoris (LCF) of the hip joint. Therefore, this in vitro study examined the presence and compared the differentiation potential of MPCs isolated from the bone marrow, arthritic hyaline cartilage, the LCF and full-thickness samples of the anterior joint capsule of the hip joint.

Methods: MPCs were isolated and multiplied in adherent monolayer cell culture. Osteogenesis and adipogenesis was induced in monolayer cell cultures for 21 days using a differentiation medium containing specific growth factors, while chondrogenesis in the presence of TGF- $\beta 1$ was performed using pellet-culture for 27 days. Control cultures were maintained for comparison over the same duration of time. The differentiation process was analyzed using histological and immunohistochemical stainings as well as semiquantitative RT-PCR for measuring the mean expression levels of tissue-specific genes.

Results: This in vitro research showed that the isolated cells from all four donor tissues grew plastic adherent and showed similar adipogenic and osteogenic differentiation capacity as proven by the histological detection of lipid droplets or deposits of extracellular calcium and collagen type I. After 27 days of chondrogenesis proteoglycans accumulated in the differentiated MPC-pellets from all donor tissues. Immunohistochemical staining revealed vast amounts of collagen type II in all differentiated MPC-pellets, except for those from the LCF. Interestingly all differentiated MPCs still showed a clear increase in mean expression of adipogenic, osteogenic and chondrogenic marker genes. In addition the examination of an exemplary donor sample revealed that cells from all four donor tissues were clearly positive for the surface markers CD44, CD73, CD90 and CD105 by flow cytometric analysis.

Conclusions: This study proved the presence of MPCs in all four examined donor tissues of the hip joint. No significant differences were observed during osteogenic or adipogenic differentiation depending on the source of MPCs used. Further research is necessary to fully determine the chondrogenic differentiation potential of MPCs isolated from the LCF and capsule tissue of the hip joint.

\section{Background}

Tissue loss as well as organ failure due to traumatic, congenital or acquired diseases pose a substantial health threat to our modern society [1-3]. Despite medical innovations enabling the transplantation of allogenic tissue and organs, according to the World Health Organization (WHO) there is a substantial lack in potential donors [1, 4]. Even more important constant increases in life expectancy have led to a skyrocketing of degenerative diseases which generate both severe expenses for our health care systems and a growing amount of patients that could benefit from progress in the area of regenerative medicine $[2,3,5]$. These challenges have led to constant new research in the field of Tissue Engineering (TE) $[6,7]$. TE aims to regenerate or maintain tissue function through the combined use of living cells as well as biomaterials and specific growth factors or signalling pathways to guide or maintain cell fate [7]. 
Disorders of the locomotive system, such as soft tissue defects, diseases of the skelletal systeme and loss of articular cartilage as seen in osteoarthritis, majorly contribute to the rise of chronic, degenerative diseases that are subject to TE [8, 9]. Especially the poor capacity for self-regeneration of articular cartilage has been subject to various in vitro and in vivo research $[8,10]$. While current techniques for cellbased cartilage repair such as autologous chondrocyte transplantation (ACT) have shown beneficial results in the short-term, still there is no reliable technique to restore long-lasting hyaline cartilage in vivo [11-13]. In addition, the harvest of mature, autologous-derived cells from healthy tissue causes iatrogen damage at the extraction site and often requires invasive surgery while only offering a small yield of cells [12].

In contrast to mature cells mesenchymal stromal cells (MSCs) offer an extensive multipotent differentiation potential, while vast amounts of MSCs can be isolated from easy accessible tissues minimizing donor site morbidity [14]. Further unlike stem cells they raise less ethical questions and carry less risk of cancer formation after transplantation $[15,16]$. The minimal requirements cells have to meet to be viewed as MSCs were defined by the International Society for Cellular Therapy (ISCT) in 2006 [17, 18]. These criteria include the expression ( $\geq 95 \%$ positive) of the surface molecules CD73, CD 90 and CD105 as well as the lack of expression ( $\leq 2 \%$ positive) of haematopoetic cell markers. Furthermore, MSCs have to grow plastic-adherent and show the ability to differentiate into osteoblasts, adipocytes and chondroblasts in vitro which is why they are frequently used for engineering osteochondral or soft tissue $[17,18]$.

When comparing sources of MSC, bone marrow-derived MSCs (BMSCs) are often viewed as the gold standard. Still there is a variety of easy accessible sources for MSCs such as adipose, synovial or perinatal tissue offering a comparable differentiation capacity while causing minimal donor site morbidity $[5,19]$. Therefore, the goal of this in vitro-study was to further contribute to this subject by proving the presence and comparing the multipotent differentiation potential of mesenchymal progenitor cells (MPCs) in the bone marrow, articular cartilage, full-thickness samples of the joint capsule and the ligamentum capitis femoris (LCF) of the arthritic human hip joint.

Recently, the term MSCs was frequently discussed questionning if it is still up-to-date [20]. Origininally the term MSCs was used as an abbreviation for mesenchymal stem cells which appears inappropriate since MSCs do not function as multipotent stem cells in vivo [20]. Newer studies also queried their description as MSCs that based on the belief that these multipotent cells were found in the stromal section of tissues rising from the mesodermal lineage. The reason for this is that more recent findings suggested MSCs rise from pericytes located in the perivascular region of various adult tissues [20,21]. To avoid confusion multipotent precursor cells examined in this study will be reffered to as MPCs.

\section{Methods}

\section{Isolation and cultivation of MPCs}


As described earlier, after informed consent and as approved by University of Wuerzburg's institutional review board MPCs were isolated from the femoral marrow reamings, arthritic femoral cartilage, as well as full-thickness samples of the hip joint's anterior capsule and LCF of five female patients aged 40 to 55 (meag age 49 years), that underwent total hip replacement surgery [22, 23]. To summarize the process collected tissues were preparated into small sized pieces that were then digested using collagenase ( $0.175 \mathrm{U} / \mathrm{mL}$; Serva Electrophoresis, Heidelberg, Germany) in Dulbecco's Modified Eagle Medium (DMEM)/Ham's F12 (1:1; Life Technologies GmbH, Thermo Fisher Scientific, Waltham, Massachusetts). In addition, samples of each tissue were secured to perform Hematoxylin-Eosin (H\&E) staining. The cells were then spun, resuspended and disseminated in $175 \mathrm{~cm}^{2}$ plastic cell culture flasks (Greiner Bio-One $\mathrm{GmbH}$, Frickenhausen, Germany). They were covered in standard culture medium consisting of DMEM/Ham's F12, supplemented with $10 \%$ fetal bovine serum (FBS) and $1 \%$ penicillin/streptomycin (PS) (all Life Technologies, Thermo Fischer Scientific, Dreieich, Germany). When the cells reached confluency, they were trypsinated and stored in cryo tubes (Greiner Bio-One $\mathrm{Gmbh}$ ) at $-80^{\circ} \mathrm{C}$ for later experiments, dissolved in a medium consisting of 50\% FBS, 40\% DMEM/Ham's F12 and 10\% dimethylsulfoxid (DMSO; AppliChem GmbH, Darmstadt, Germany).

\section{FACS analysis of surface antigens}

The cells were washed in phosphat buffered saline (PBS), spun and resuspended in standard cell culture medium. After this, cells were counted and seperated into two 2,5 mL eppendorf tubes (Greiner Bio-One $\mathrm{GmbH}$ ) per tissue sample. Each of the two eppendorf tubes contained a minimum amount of $5 \times 10^{5}$ cells per tissue sample. After this $100 \mu \mathrm{L}$ of an antibody-PBS mixture containing a PBS/1\% FBS pre-mix, CD 73 PerCP antibody, CD44 eFLuor antibody, CD105 APC antibody and CD90 FITC antibody (all Thermo Fisher Scientific $\mathrm{GmbH}$, Dreieich, Germany) was added to one of these two samples for fluorescence-activated cell sorting (FACS) analysis. The other sample was only provided with $100 \mu \mathrm{L}$ of PBS/ $1 \%$ FBS pre-mix and was therefore treated as a negative control. Both samples were then vortexed, stored in the dark $\left(4{ }^{\circ} \mathrm{C}\right.$ for $30 \mathrm{~min}$ ), washed in PBS/1\% FBS, spun and resuspended in 2\% paraformaldehyd in PBS before being stored in the dark again ( $4{ }^{\circ} \mathrm{C}$ for $15 \mathrm{~min}$ ). Finally, the cells were washed in PBS, spun, resuspended in $\mathrm{PBS} / 1 \% \mathrm{FBS}$ and vortexed. The two samples were now ready for FACS analysis which was performed with the BDTM LSR II X device (BD biosciences, Franklin Lakes, NJ, USA) and analyzed using the FlowJo 10.5.3 Software (FlowJo LLC, Ashland, OR, USA).

\section{Adipogenic and osteogenic differentiation}

The MPCs stored at $-80^{\circ} \mathrm{C}$ were defrosted and disseminated in standard cell culture medium in plastic cell culture bottles until reaching confluency. Briefly, the cells were then trypsinated, counted and seeded in six-well plates (Greiner Bio-One $\mathrm{GmbH}$, Frickenhausen, Germany) at a density of $3 \times 10^{3}$ cells per $\mathrm{cm}^{2}$. Aditionally, MPCs were seeded in two-chamber slides (Greiner Bio-One GmbH, Frickenhausen, Germany) at a density of $5 \times 10^{3}$ cells per chamber for immunohistochemical stainings. Cell cultures were stored at $37^{\circ} \mathrm{C}, 5 \% \mathrm{CO}_{2}$ and medium changes were performed every 3 to 4 days (d). After the cells showed confluent growth osteogenesis and adipogenesis were induced as described in previous studies [24, 25]. 
Other wells and chambers were covered with standard culture medium to maintain controls for comparison to the differentiated MPCs. The cell cultures were fixed after $21 \mathrm{~d}$.

To detect mineralization of the extracellular matric (ECM) Alizarin Red S (1\%; Sigma-Aldrich) stainings were performed as reported previously [25], while immunohistochemical stainings were used to reveal extracellular collagen type I (Col I) formations. The adipogenic differentiation was detected through staining of lipid drops using Oil RedO (all Sigma-Aldrich) as described previousely [26]. In addition, the gene expression levels of the tissue specific osteogenic marker genes alkaline phosphatase (ALP), Col I, collagen type $\mathrm{X}(\mathrm{Col} \mathrm{X}$ ) or osteocalcin (OC), as well as the adipogenic marker genes lipoproteinlipase (LPL) and peroxisome proliferator-activated receptor $\mathrm{Y}$ (PPARY) were examined with RT-PCR.

\section{Chondrogenic differentiation}

To further confirm the multilineage differentiation potential of the isolated cells their chondrogenic differentiation potential was tested using pellet culture as described previously [27]. Pellets were covered in chondrogenic differentiation medium as reported earlier [24]. Four pellets per tissue sample were formed for chondrogenic differentiation while four more were maintained in a control medium missing transforming growth factor (TGF)- $\beta 1$. The beakers were then centrifuged to promote aggregate formation and stored at $37^{\circ} \mathrm{C}, 5 \% \mathrm{CO}_{2}$ while medium changes were performed every 3 to $4 \mathrm{~d}$. After $27 \mathrm{~d}$ of culture the pellets were placed in Tissue-Tek ${ }^{\circledR}$ Cryomold $^{\circledR}$ Standard (Sakura Fintek, Torrance, CA, USA) before being shock frozen in liquid nitrogen. The frozen pellets were sectioned at $6 \mu \mathrm{m}$ thickness and placed on SuperFrost ${ }^{\circledR}$ cryosection slides (Thermo Fischer Scientific $\mathrm{GmbH}$ ). To fix the cells the pellets were covered in $3 \%$ acetic acid (3 $\mathrm{min}$; Carl Roth $\mathrm{GmbH}$ ). Alcian blue (1\%, Sigma-Aldrich) stainings were performed to verify the formation of proteoglycans as described earlier [28]. Immunohistochemical stainings were used to detect collagen type II (Col II) and Col X. The expression of chondrogenic markers aggrecan (AGG), Col II and sex-determining region Y-box 9 (Sox-9) was tested with RT-PCR.

\section{Histology and Immunohistochemistry}

Native tissue samples were fixed in $4 \%$ paraformaldehyde, dehydrated and embedded in paraffin. They were then sectioned and stained with H\&E (Sigma-Aldrich) as described in earlier studies [22]. Monolayers were fixed in ice-cold methanol, while pellet cultures were placed in Tissue-Tek ${ }^{\circledR}$ Cryomold $^{\circledR}$ Standard (Sakura Fintek, Torrance, CA, USA) before being shock frozen in liquid nitrogen. The frozen pellets were sectioned, placed on SuperFrost ${ }^{\circledR}$ cryosection slides (Thermo Fischer Scientific GmbH) and fixed with $3 \%$ ice-cold acetone (Carl Roth $\mathrm{GmbH}$ ). Alizarin Red S, Oil redO and alcian blue stainings were performed as outlined previously $[25,26,28]$. In addition, immunohistochemical stainings were performed on monolayers and pellets using the following antibodies: Col I- monoclonal anti Col la1 ( $5 \mu \mathrm{g} / \mathrm{mL}$; Abcam pls, Cambridge, Great Britain); Col II - polyclonal Col lla1 antibodies ( $5 \mu \mathrm{g} / \mathrm{mL}$; Acris Antibodies $\mathrm{GmbH}$, Herford, Germany); Col X - polyclonal Col X antibodies ( $5 \mu \mathrm{g} / \mathrm{mL}$; Abcam pls). The immunostainings were visualised with the Avidin-Biotion complex method using the protocols, biotinylated antibodies, blocking serum and peroxidase from the VECTASTAIN ${ }^{\circledR}$ Universal Elite ${ }_{\circledast} A B C$ Kit (Vector Laboratories, Burlingame, 
CA, USA) and the VECTOR ${ }^{\circledR}$ NovaRED ${ }^{\text {TM }}$ peroxidase substrate kit (Vector Laboratories). The slides and wells were counterstained with hemalaun. For control stainings the primary antibodies were replaced with non-immune IgG antibodies (Sigma-Aldrich).

\section{RNA isolation and semiquantitative RT-PCR analysis}

RNA was isolated from control and differentiated samples of adipogenic, osteogenic (21 d) and chondrogenic (27 d) MPCs using Trizol reagent (Invitrogen), as well as further purification steps, including DNase treatment, as described in the user's guide (NucleoSpin ${ }^{\circledR}$ RNA II kit, Macherey-Nagel GmbH \& Co. KG, Düren, Germany). To create cDNA $1 \mu \mathrm{g}$ of purified RNA was combined with random hexamer primers (Thermo Fischer Scientific) and Promega ${ }^{\circledR}$ M-MLV reverse transcriptase (Promega GmbH, Mannheim, Germany). $1 \mu \mathrm{L}$ of cDNA served as a pattern for amplification in a $30 \mu \mathrm{L}$ reaction volume containing $\mathrm{GoTaq}^{\circledR}$ DNA polymerase (Promega $\mathrm{GmbH}$ ) with forward and reverse gene-specific primers (5 pmol each). The primers and their specific sequences, annealing temperatures and cycle numbers are listed in Table 1. Elongation factor $1 \mathrm{a}$ (EEF 1a) was used as the housekeeping gene. The final products of RT-PCR were seperated through electrophoresis on $2 \%$ agarose (Biozym Scientific $\mathrm{GmbH}$, Hessisch Oldendorf, Germany) gels containing $5 \mu \mathrm{L}$ per $100 \mathrm{~mL}$ GelRed ${ }^{\circledR}$ (Biotium, Fremont, CA, USA). The band densities for each primer pair were then examined to measure the mean ratio and standard deviation for all of the tested genes in comparison to the expression of the EEF 1 a housekeeping gene.

\section{Statistical analysis}

Semiquantitative RT-PCR experiments were performed on four different tissues all taken from five different donors $(n=5)$ and expressed as mean values standard deviation. Statistical significance was defined using the Student's $t$ test with $p<0,05$ being considered as significant.

\section{Results}

\section{H\&E stainings of native tissue samples}

H\&E staining was succesfully performed on all collected native tissue samples from bone marrow, hyaline cartilage, LCF and the joint capsule, coloring acidophile structures red and basophile structures blue (Figure 1). Stained bone marrow tissue samples (Figure 1, bone marrow), derived from the femoral reaming, showed parts of bone trabeculae that were composed of collagen fibres and osteocytes. In addition, osteoblasts could be assumed at the periphery of bone trabeculae. Samples from degenerated, arthritic hyaline cartilage (Figure 1, cartilage) revealed few chondrones that consisted of condrocytes in lacunaes. These chondrones were surrounded by an irregularly, basophilic stained ECM. The LCF (Figure 1, LCF) mainly consisted of connective tissue formed by collagen fibres, fibrous and adipose tissue. This connective tissue contained blood vessels of varying size and was coated by synovium. Similar to the LCF the joint capsule (Figure 1, capsule) consisted of a fibrous and synovial stratum. The fibrous stratum was formed by connective, ligamentous tissue built by collagen fibres and adipose tissue and filled with 
numerous small blood vessels. The thin synovial stratum coated the fibrous stratum and formed folds, the so-called plicae synoviales. In both the LCF (Figure 1, LCF) and the joint capsule (Figure 1, capsule) fibroblasts appeared as spindle shaped cells in the connective tissue. Mononuclear cell infiltration was observed around small blood vessels of the fibrous stratum in the tissue samples derived from the joint capsule (Figure 1, capsule).

\section{Surface markers on isolated MPCs}

FACS analysis was performed (Figure 2) using cells from all four tissue samples of a single donor to exemplary define the percentage of isolated cells that expressed the surface antigens CD44, CD73, CD90 and CD105 (Table 2). All isolated cells from bone marrow, cartilage, LCF and the joint capsule were strongly positive ( $\geq 95 \%$ ) for CD44, CD90 and CD105 (Table 2, CD44 ${ }^{+}, \mathrm{CD}^{+}, \mathrm{CD} 105^{+}$). The majority of isolated cells was also strongly positive $(<95 \%)$ for the surface marker CD73 (Table 2, CD73 ${ }^{+}$). While > $70 \%$ of cells isolated from bone marrow, cartilage and the joint capsule expressed CD73, only about half of the cells from the LCF were positve for this surface marker $\left(\right.$ Table $\left.2, C D 73^{+}\right)$. Matching results were shown within the coexpression of CD-antigens (Figure 2; Table 2).

\section{Histological analysis of adipogenic differentiation}

In comparison to control cultures (Figure 3, b, control d 21) all cells derived from bone marrow, cartilage, the joint capsule and the LCF which were incubated in an adipogenic differentiation medium for $21 \mathrm{~d}$ showed positive Oil RedO stainings (Figure 3, b, differentiation d 21). The quantity of lipid droplets in all adipogenic differentiated cultures increased from d 12 (Figure 3, a, diff. d 12) to d 21 (Figure 3, a, diff. d 21). The total amount of adipocyte-like cells after $21 \mathrm{~d}$ was higher in culutres containing differentiated cells from the LCF and the joint capsule (Figure 3, LCF, capsule) than compared to those from bone marrow and cartilage (Figure 3, bone marrow, cartilage), as shown in representative areas.

\section{Adipogenic marker gene expression after $21 \mathrm{~d}$}

After $21 \mathrm{~d}$ the adipogenic differentiated cultures from all four donor tissues showed a similar, clear upregulated mean value of mRNA expression levels of adipogenic marker genes lipoproteinlipase $(\mathrm{LPL})$ and peroxisome proliferator-activated receptor $\mathrm{Y}$ (PPARY) in comparison to their controls (Figure 4, a). The mean expression levels of LPL in cells from LCF (Figure 4, a, LPL) and PPARY in MPCs from the joint capsule (Figure 4, a, PPARY) were lower than in cartilage or bone marrow-derived cells, although none of these findings were significant.

\section{Histological and immunohistochemical analysis of osteogenesis}

From d 12 (Figure 5, a, diff. d 12) to d 21 (Figure 5, a, diff. d 21) spider web-like cell patterns, surrounded by an increasing amount of extracellular, dense deposits formed in all monolayers incubated in osteogenic differentiation medium. After $21 \mathrm{~d}$ positive Alizarin Red S staining identified these dense depostis as calcium aggregates in all osteogenic differentiated cell-cultures from bone marrow, cartilage, 
the joint capsule and LCF (Figure 3, b, differentiation d 21). In addition, all osteogenic differentiated cultures showed a clearly positive, immunohistochemical staining for Col I at the end of the differentiation period after $21 \mathrm{~d}$ (Figure 5, c, differentiation d 21). Controls remained negative for both Alizarin Red S (Figure 5, b, control d 21) and immunohistochemical stainings (Figure 5, c, control d 21).

\section{Osteogenic marker gene expression after $21 \mathrm{~d}$}

RT-PCR revealed an upregulation of the mean mRNA expression levels of osteogenic marker genes collagen type $X(\mathrm{Col} X)$, alkaline phosphatase (ALP) and osteocalcin (OC) in all of the osteogenic differentiated cultures compared to their controls (Figure 4, b). The expression of the osteogenic marker gene OC in MPCs derived from bone marrow was significantly higher $(p<0,05)$ than from MPCs isolated from cartilage (Figure 4, b, OC). Interestingly, the mean expression levels of Col I mRNA in comparison to negative controls only showed a significant increase in MPCs derived from bone marrow (Figure 4, b, Col I). Other than that, the expression of osteogenic marker genes did not differ significantly within MPCs derived from different native tissues. These findings are contrary to the clearly positive immunohistochemical stainings for Col I in all osteogenic differentiated MPCs (Figure 5, c, differentiation d 21).

\section{Histological and immunohistochemical analysis of chondrogenesis}

After $27 \mathrm{~d}$ of pellet-culture in presence of TGF-ß1, positive alcian blue stainings proved the presence of proteoglycans in all chondrogenic differentiated cell-pellets derived from bone marrow, cartilage, the joint capsule and LCF (Figure 6, a, differentiation d 27). In addition, chondrogenic differentiated pellets containing cells from bone marrow and cartilage showed a chondrogenic phenotype especially in outer regions of the pellets (Figure 6, a, bone marrow, cartilage). Despite clearly postive alcian blue stainings, hyaline cartilage-specific attributes, such as chondrones in areas with a low density of cells, were less visible in pellets from the joint capsule (Figure 6, a, capsule) and almost non-existent in pellets from LCF (Figure 6, a, LCF). Corresponding to alcian blue stainings immunohistochemical stainings revealed vast amounts of collagen type II (Col II) in outer regions of the differentiated pellets from bone marrow, cartilage and the joint capsule after $27 \mathrm{~d}$ (Figure 6, b, differentiation d 27). In comparison to the strong immunohisochemical stainings of Col II in differentiated pellets from bone marrow and cartilage (Figure $6, \mathrm{~b}$, bone marrow, cartilage) the staining appeared less intense in differentiated pellets from the joint capsule (Figure 6, b, capsule). In contrast, chondrogenic differentiated pellets from LCF showed no visible stainings of Col II after $27 \mathrm{~d}$ (Figure 6, b, LCF). All controls remained negative for alcian blue (Figure 6, a, control d 27) and Col II (Figure 6, b, control d 27) stainings after $27 \mathrm{~d}$ of pellet culture in absence of TGFß1.

Immunohistochemical stainings for Col $\mathrm{X}$ were performed to examine possible chondrocyte hypertrophy during chondrogenic differentiation (Figure 6, c). While controls remained mostly negative (Figure 6, c, control d 27), differentiated pellets showed slightly stronger stainings especially in inner, cell-rich regions of the sections (Figure 6, c, differentiation d 27) that showed a less chondrogenic phenotype in earlier 
alcian blue and Col II stainings. The strongest matrix staining for Col $\mathrm{X}$ after $27 \mathrm{~d}$ was seen in the differentiated pellets containing cells from cartilage (Figure 6, c, cartilage).

\section{Expression of chondrogenic marker genes after $27 \mathrm{~d}$ of pellet-culture}

RT-PCR showed an upregulation of the mean mRNA levels of the examined chondrogenic marker genes AGG, Col II and Sox-9 in all chondrogenic differentiated pellets after $27 \mathrm{~d}$ (Figure 4, c). The mean mRNA expression levels of AGG and Col II were highest in chondrogenic differentiated pellets from the joint capsule although observed differences were not from statistical significance (Figure 4, c, AGG, Col II). Interestingly, the mean expression of Col II mRNA was upregulated in differentiated pellets from LCF (Figure 4, c, Col II) although the immunohistochemical stainings remained negative for Col II in corresponding pellets from LCF (Figure 6, b, LCF). Significant differences in the mean mRNA expression levels between the pellets from varying native tissues were not observed.

\section{Discussion}

Due to the tripotent differentiation capacity of MPCs they possess huge potential for the regenerative, cell-based treatment of musculoskeletal or soft tissue defects as well as traumatic or degenerative cartilage disorders $[13,29]$. Since MPCs were first isolated from bone marrow by Friedenstein et al. they have been found to residue in a variety of adult or perinatal-derived tissues [19, 30, 31]. Interestingly, MPCs isolated from easy accesible, abundant sources, such as adipose or synovial tissue, have shown to possess a potentially superior differentiation capacity compared to bone marrow-derived MPCs (BMPCs) and thus sparked great interest among clinicians and researchers [19, 32]. These MPC-subpopulations, which can be harvested causing minimal donor site morbidity while offering a high yield of cells from native tissues, could lead to substantial progress in TE when combined with smart biomaterials and suitable growth factors $[3,5]$. Therefore, the goal of this study was to further contribute to the detection and examination of innovative and valuable sources of multipotent precursor cells. In order to do so the LCF and full-thickness samples of the joint capsule in arthritic human hip joints were examined regarding the presence of MPCs. The characteristics of isolated cells were then compared to better-known sources of MPCs simultaneously derived from bone marrow and arthritic hyaline cartilage of the same hip joints as well as similar MPC-subpopulations analyzed in earlier studies. In addition, the characterization of cells isolated from all four donor tissues was set in relation to the ISCT's minimal criteria for the definition of MSCs.

First and formost, our study showed that multipotent, plastic-adherent growing cells could be isolated from bone marrow, arthritic hyaline cartilage, the LCF and full-thickness samples of the joint capusles of the examined arthritic hip joints. Further cells cells from an exemplary tested donor sample were clearly positive for the surface antigens CD44, CD73, CD90 and CD105 independent of utilised native tissue. The presence of BMPCs $[26,33]$ and MPCs found in the superficial zone of arthritic or healthy hyaline cartilage $[34,35]$ has been frequently confirmed through earlier in vitro-studies, matching our findings. While MPCs have previously also been obtained from the joint capsule of the human hip, interestingly, the 
tissue utilized for the isolation of cells was exclusively derived from the synovial stratum [36]. In addition, there is no data exclusively describing the characterization of MPCs isolated from the LCF, although Steinert et al. and Cheng et al. described the isolation of MPCs from the anterior cruciate ligament (ACL) of the knee in earlier studies [24,37]. Even though the two ligaments are not identical the ACL and the LCF share various histological and anatomical similarities and both form intraarticular ligaments in synovial joints coated by a synovial membrane [38]. Regardless, both of these findings support the complementary and novel results in our study in which MPCs could be isolated from the LCF and fullthickness tissue samples of the arthritic hip's joint capsule, including the ligamentous tissue of the fibrous stratum. Moreover, all four tissues examined in our study rise from the LPM and are well vascularized, making them home to pericytes. Considering the current knowledge about the embryonic developement of MPCs this supports our studies results [20]. Hyaline cartilage represents an exception since it is avascular. This led to previous debates about if multipotent precursors, which have been shown to be located close to the surface in arthritic and healthy hyaline cartilage, may be distinct from MPCs or whether precursors other than PSCs contribute to the formation of MPCs [20,39].

Secondly, we found that $\geq 95 \%$ of the examined cells derived from bone marrow, hyaline cartilage, the joint capsule and the LCF of one representative donor showed a clearly positive expression of CD44, CD90 and CD105 as shown through FACS analysis. Although a large number of isolated cells were also positive for $C D 73$, the percentage did not exceed $95 \%$ independent of the type of donor tissue. This means that all isolated cells of the exemplary chosen donor carried a compilation of surface antigens which is viewed as highly characteristic for multipotent precursor cells described as MSCs [18]. The presence of these surface markers on BMPCs has previously been proved in various studies [33, 40-42]. Alsalameh et al. and Pretzel et al. also showed that MPCs derived from healthy and arthtitic cartilage, coexpress the MSC-like surface markers CD105 and CD166 [34, 35]. Multiple researchers also isolated MPCs expressing the surface antigens $C D 73, C D 90$ and $C D 105$ from the $A C L[24,37]$ or the synovial membrane and synovial fluid of the hip joint's capsule $[19,43,44]$. This strongly supports our findings in which cells expressing the surface markers CD44, CD73, CD90 and CD105 can also be found in fullthickness samples of the joint capsule and LCF of the human hip joint. Nonetheless, independant of the utilised native tissue the representative cells examined in our study did not fully meet the ISCT's minimal criteria for the definition of MSCs in vitro since the percentage of cells positive for CD73 did not exceed $95 \%$ and cells were not tested negative $(\leq 2 \%)$ for haematopoetic surface markers [17]. Still cells isolated from all four tissues of the exemplary chosen donor clearly expressed MSC-like surface antigens and would most certainly fulfill the ISCT's formal criteria if further steps of purification had been performed.

Thirdly, mulitpotent differentiation potential varied but was proven for all cells isolated from bone marrow, cartilage, the joint capsule and LCF of the human hip joint as requested by the ISCT's minimal criteria for MSCs [17]. Adipogenic and osteogenic differentiation capacity, as proven by histological, immunohistochemical and molecularbiological analysis, showed hardly any significant differences between the different donor tissues of cells. Lastly, chondrogenic differentiation was induced using a TGF- $ß 1$ based differentiation medium and pellet culture system as described earlier by Johnstone et al. [45]. Three dimensional culture systems add mechanical stimuli, similar to the enchondral ossification in 
the human growth plate, that are necessary for chondrogenic differentiation in vitro [46-48]. Although MPCs derived from all four tissues showed successfull chondrogenesis in histological and molecularbiological analysis, immunohistochemical stainings of Col II (Figure 6, b) pointed towards a superior chondrogenic differentiation capacity of MPCs isolated from bone marrow and cartilage.

The trilineage differentiation capacity of BMPCs using similar methods as used in this study has been repeatedly validated and matches our findings [26,33]. Since bone marrow was the first discovered source for the isolation of MPCs in vitro it is often reffered to as the gold standard which other subpopulations of MPCs are compared to. In line with the results of our study Alsalameh et al. and Pretzel et al. showed that the adipogenic, osteogenic and chondrogenic differentiation capacity of MPCs derived from arthritic hyaline cartilage of the knee did not differ significantly from that of BMPCs [34].

Segawa et al. found that MPCs derived from synovial and subsynvoial tissue of the medial capsule of the knee joint showed similar adipogenic and osteogenic differentiation capacity compared to BMPCs [19]. Interestingly, the chondrogenic differentiation potential of these synovial derived MPCs was decleared superior to that from BMPCs as measured by mean size and dry weight of chondrogenic differentiated pellets [19]. Another study by Hatakeyama et al. compared the multipotent differentiation capacity between synovial derived MPCs from the hip and the knee joint. The results showed that while adipogenic and osteogenic differentiation capacity was significantly higher for cells isolated from the knee joint, their chondrogenic differentiation potential was similar [36]. Although we used both, the synovial stratum and also the ligamentous tissue from the fibrous stratum for the isolation of MPCs from the hip's joint capsule, these findings correspond to our results in which the multipotent differentiation capacity of joint capsule-derived MPCs mostly equaled that from BMPCs. Unfortunately pellet size and dry weight of differentiated pellets were not measured in our study not allowing a direct comparison to earlier research. Still the chondrogenic phenotype as well as the intensity of immunohistochemical stainings of Col II in differentiated pellet-sections containing BMPCs were superior to those containing cells from the joint capsule.

As mentioned above there is no scientific data about the isolation and multipotent differentiation capacity of MPCs from the LCF. Similar to the LCF in the hip, the ACL forms an intraarticular, vascularized ligament in the knee. Although of course this does not allow a fully equal treatment of MPCs derived from both tissues we compared our findings for MPCs derived from the LCF to those from studies that isolated MPCs from the ACL $[24,37]$. Matching the results of the trilineage differentiation of MPCs derived from the LCF in our study Steinert et al. found that the chondrogenic differentiation capacity of BMPCs was higher compared to cells isolated from the ACL, while their osteogenic and adipogenic differentiation potential did not differ significantly [24]. In contrast to our findings Steinert et al. found positive immunohistochemical stainings of $\mathrm{Col}$ II in chondrogenic differentiated pellet-sections containing cells derived from the ACL in the presence of TGF- 31 [24]. Although Cheng at al. found similar results regarding the adipogenic differentiation of both sources of MPCs, they reported a higher osteogenic and similar chondrogenic differentiation capacity of BMPCs compared to the cells derived from the ACL [37]. 
Finally, until today there are many uncertainties surrounding the group of multipotent precursor cells commonly described as MPCs or MSCs. These include the defining criteria for MSCs in vitro released by the ISCT as well as the functionalities, characterization and localization of potential MSCs in vivo [20]. The functional capacities of cells described as MSCs in vitro including multipotent differentiation and colony formation suggested that MSCs may represent a group of stem cells [20]. However unlike stem cells, MSCs showed limited self-renewal after multiple passages of cell culture in vitro [49]. In addition, the implantation of MSCs in vivo lead to spontaneous formation of bone tissue but not to formation of cartilage or fat, showing that the multipotent differentiation capacity of so called MSCs in vitro does not represent their functionality in vivo $[20,49]$. Due to these insights, this group of cells was no longer reffered to as mesenchymal stem cells but rather as MSCs, since they were believed to reside in the stroma of various tissues rising from the mesodermal lineage [20]. This was not wrong to assume since MSCs are closely linked to the somatic layer of the lateral plate mesoderm (LPM). Cells from the somatic layer of the LPM later form bone, cartilage, tendons and ligaments in all limbs, subcutaneous abdominal and gluteofemoral fat, as well as multipotent progenitor cells for the homeostatic preservance of these tissues [50]. While MSC-like cells have since been isolated from close to all of these tissues rising from the somatic layer of the LPM in vitro, their exact location in vivo remains unclear. Interestingly, perivascular located pericytes and adventitial progenitors cells, found in the tunica adventitia of large blood vessels, remain some of the only cells examined in situ to meet all MSC-defining criteria [51]. Hence these perivascular stem cells (PSCs), even when isolated from tissues that do not rise directly from the somatic layer of the LPM, showed adipogenic, osteogenic and chondrogenic differentiation capacity in in vitro cultures [21]. This led to the belief that contrary to what their name would suggest MSCs may not reside in the stromal tissue section but rather rise from PSCs which are located in the perivascular region of almost all tissues of the human body [21]. This challenged our earlier understandings of MSCs as tissue resident, stem cell-like cells isolated from tissues of mesodermal origin and opens up new possibilities for the use and isolation of cells commonly defiend as MSCs.

These contrasts between the characteristics of multipotent progenitor cells presented in vitro and in vivo not only led to disagreement regarding their naming but also questionned the benefits of the ISCT's minimal criteria for the definition of MSCs that solely builds on in vitro findings [18]. By introducing these minimal criteria the ISCT tried to standardise the scientific use of multipotent precursor cells and to thereby facilitate the comparison of similar cells described as MSCs [18]. However research has shown that cells meeting the criteria for MSCs derived from different origins not only present distinct compilations of surface markers but that the expression of surface antigens also changes throughout their cultivation in vitro $[39,49]$. In addition, MSCs derived from varying sources require a specific composition of growth factors for trilineage differentiation and hence vary regarding their differentiation capacity $[19,20,49]$. This raises further doubt whether the ISCT's criteria or any standardizing classification at all is adequate to define cells reffered to as MSCs and rather indicates that MSC-like cells isolated from different tissues represent subpopulations with unique tissue-specific characteristics that offer both advantages and disadvantages for their clinical use [39, 52]. 
Finally all cells isolated from bone marrow, articular cartilage, the LCF and the joint capsule of arthritic hip joints grew plastic-adherent and were capable of differentiation into adipocytes, osteocytes and chondrocytes. In addition, all cells from the examined representative donor samples expressed the surface antigens CD44, CD73, CD90 and CD105 which are viewed as characteristic for MSCs. Nonetheless, since cells from the exemplary tested donor sample did not fully meet the ISCT's minimal criteria regarding the expression of the surface antigen $\mathrm{CD73}$, along with the mentioned confusion surrounding the correct naming of multipotent progenitor cells, we reffered to the isolated cells as MPCs. The findings in this study represent information gathered in vitro and may not fully correspond to the in vivo functionalities of examined cell subpopulations. Therefore, additional in vitro-studies are necessary to fully determine suitable growth factors and fitting biomaterials to optimize the chondrogenic differentiation of MPCs derived from full-thickness samples of the joint capsule and the LCF. When considering the most suitable source of MPCs for clinical use one has to bear in mind the donor site morbidity caused by the isolation of these cells as well as the varying yield obtained from different tissues $[19,39]$. Ultimately the target for all inidcations of tissue engineering is to identify the fitting source of MPCs, offering the best desired differentiation capacity, while causing the least donor site morbidity during withdrawal. This study adds further evidence and information to possible sources of MPCs and their characteristics in vitro.

\section{Conclusions}

All examined tissues of the arthritic hip joint - bone marrow, arthritic hyaline cartilage, LCF and the joint capsule - were proved to be home to multipotent, plastic adherent growing and CD44, CD73, CD90, CD105 positive MPCs. Due to the percentage of CD73 positive cells in all isolated multipotent progenitor cells independent of their origin, they did not fully meet the minimal criteria for MSCs definded by the ISCT in 2005. While the osteogenic and adipogenic differentiation potential showed no significant differences depending on the source of MPCs used, further research is necessary to fully determine the chondrogenic differentiation potential of MPCs isolated from LCF and full-thickness samples of the hip's joint capsule in vitro.

\section{Abbreviations}

ACL: anterior cruciate ligament; AGG: aggrecan; ALP: alkaline phosphatase; BMSCs: bone marrow-derived mesenchymal stromal cells; BMPCs: bone marrow-derived multipotent progenitor cells; $C D$ : cluster of differentiation; cDNA: complementary DNA; Col I: collagen type I; Col II: collagen type II; Col X: collagen type X; d: days; DMSO: dimethylsulfoxid; ECM: extracellular matrix; EEF1a: Elongation factor 1a; FACS: fluorescence-activated cell sorting; FBS: fetal bovine serum; H\&E: Hematoxylin-Eosin; ISCT: International Society for Cellular Therapy; LCF: ligamentum capitis femoris; LPL: lipoproteinlipase; LPM: lateral plate mesoderm; MPCs: mesenchymal progenitor cells; MSCs: mesenchymal stromal cells; OC: osteocalcin; PBS: phosphat buffered saline; PPARY: peroxisome proliferator-activated receptor $\gamma$; PS: 
penicillin/streptomycin; PSCs: perivascular stem cells; RT-PCR: reverse transcriptase polymerase chain reaction; Sox-9: sex-determining region Y-box 9; TGF: transforming growth factor;

\section{Declarations}

Acknowledgements

We are grateful to Beate Geyer and Jutta Schneidereit for their excellent technical assistance.

Authors' contributions

All authors have read and approved the manuscript and contributed to the study design, data analysis, interpretation of data and drafting and revision of the manuscript. MIW performed the experiments. MIW and MAW wrote the manuscript and designed the tables and figures. The authors read and approved the final manuscript.

Funding

This publication was funded by the German Research Foundation (DFG) and the University of Wuerzburg in the funding programme Open Access Publishing.

Availability of data and materials

The datasets used and analysed during the current study are available from the corresponding author on reasonable request.

Ethics approval and consent to participate

The study design and experiments were approved by University of Wuerzburg's institutional review board. In addition, participating patients agreed to the use of collected and examined surgical waste after undergoing total hip replacement surgery.

Consent for publication

Not applicable.

Competing interests

The authors declare they have no competing interests.

\section{References}

1. Dzobo, K., et al., Advances in Regenerative Medicine and Tissue Engineering: Innovation and Transformation of Medicine. Stem Cells Int, 2018. 2018: p. 2495848. 
2. Jessop, Z.M., et al., Transforming healthcare through regenerative medicine. BMC Med, 2016. 14(1): p. 115.

3. Sharma, P., et al., Tissue Engineering; Current Status \& Futuristic Scope. J Med Life, 2019. 12(3): p. 225-229.

4. Keeping kidneys. Bull World Health Organ, 2012. 90(10): p. 718-9.

5. Berebichez-Fridman, R. and P.R. Montero-Olvera, Sources and Clinical Applications of Mesenchymal Stem Cells: State-of-the-art review. Sultan Qaboos Univ Med J, 2018. 18(3): p. e264-e277.

6. Giwa, S., et al., The promise of organ and tissue preservation to transform medicine. Nat Biotechnol, 2017. 35(6): p. 530-542.

7. Berthiaume, F., T.J. Maguire, and M.L. Yarmush, Tissue engineering and regenerative medicine: history, progress, and challenges. Annu Rev Chem Biomol Eng, 2011. 2: p. 403-30.

8. Zylinska, B., et al., Treatment of Articular Cartilage Defects: Focus on Tissue Engineering. In Vivo, 2018. 32(6): p. 1289-1300.

9. Tatara, A.M. and A.G. Mikos, Tissue Engineering in Orthopaedics. J Bone Joint Surg Am, 2016. 98(13): p. 1132-9.

10. Bauge, C. and K. Boumediene, Use of Adult Stem Cells for Cartilage Tissue Engineering: Current Status and Future Developments. Stem Cells Int, 2015. 2015: p. 438026.

11. Kuroda, R., et al., Treatment of a full-thickness articular cartilage defect in the femoral condyle of an athlete with autologous bone-marrow stromal cells. Osteoarthritis Cartilage, 2007. 15(2): p. 226-31.

12. Steinert, A.F., et al., Major biological obstacles for persistent cell-based regeneration of articular cartilage. Arthritis Res Ther, 2007. 9(3): p. 213.

13. Im, G.I., Tissue Engineering in Osteoarthritis: Current Status and Prospect of Mesenchymal Stem Cell Therapy. BioDrugs, 2018. 32(3): p. 183-192.

14. Friedenstein, A.J., S. Piatetzky, II, and K.V. Petrakova, Osteogenesis in transplants of bone marrow cells. J Embryol Exp Morphol, 1966. 16(3): p. 381-90.

15. Pera, M.F., Stem cells: The dark side of induced pluripotency. Nature, 2011. 471(7336): p. 46-7.

16. Ding, D.C., et al., Human umbilical cord mesenchymal stem cells: a new era for stem cell therapy. Cell Transplant, 2015. 24(3): p. 339-47.

17. Dominici, M., et al., Minimal criteria for defining multipotent mesenchymal stromal cells. The International Society for Cellular Therapy position statement. Cytotherapy, 2006. 8(4): p. 315-7.

18. Horwitz, E.M., et al., Clarification of the nomenclature for MSC: The International Society for Cellular Therapy position statement. Cytotherapy, 2005. 7(5): p. 393-5.

19. Sakaguchi, Y., et al., Comparison of human stem cells derived from various mesenchymal tissues: superiority of synovium as a cell source. Arthritis Rheum, 2005. 52(8): p. 2521-9.

20. Caplan, A.I., Mesenchymal Stem Cells: Time to Change the Name! Stem Cells Transl Med, 2017. 6(6): p. $1445-1451$. 
21. Crisan, M., et al., A perivascular origin for mesenchymal stem cells in multiple human organs. Cell Stem Cell, 2008. 3(3): p. 301-13.

22. Steinert, A.F., et al., Hypertrophy is induced during the in vitro chondrogenic differentiation of human mesenchymal stem cells by bone morphogenetic protein-2 and bone morphogenetic protein-4 gene transfer. Arthritis Res Ther, 2009. 11(5): p. R148.

23. Noth, U., et al., In vitro engineered cartilage constructs produced by press-coating biodegradable polymer with human mesenchymal stem cells. Tissue Eng, 2002. 8(1): p. 131-44.

24. Steinert, A.F., et al., Mesenchymal stem cell characteristics of human anterior cruciate ligament outgrowth cells. Tissue Eng Part A, 2011. 17(9-10): p. 1375-88.

25. Reichert, J.C., et al., Synergistic effect of Indian hedgehog and bone morphogenetic protein-2 gene transfer to increase the osteogenic potential of human mesenchymal stem cells. Stem Cell Res Ther, 2013. 4(5): p. 105.

26. Noth, U., et al., Multilineage mesenchymal differentiation potential of human trabecular bone-derived cells. J Orthop Res, 2002. 20(5): p. 1060-9.

27. Penick, K.J., L.A. Solchaga, and J.F. Welter, High-throughput aggregate culture system to assess the chondrogenic potential of mesenchymal stem cells. Biotechniques, 2005. 39(5): p. 687-91.

28. Steinert, A.F., et al., Characterization of bursa subacromialis-derived mesenchymal stem cells. Stem Cell Res Ther, 2015. 6: p. 114.

29. Mafi, R., et al., Sources of adult mesenchymal stem cells applicable for musculoskeletal applications - a systematic review of the literature. Open Orthop J, 2011. 5 Suppl 2: p. 242-8.

30. da Silva Meirelles, L., P.C. Chagastelles, and N.B. Nardi, Mesenchymal stem cells reside in virtually all post-natal organs and tissues. J Cell Sci, 2006. 119(Pt 11): p. 2204-13.

31. Joerger-Messerli, M.S., et al., Mesenchymal Stem Cells from Wharton's Jelly and Amniotic Fluid. Best Pract Res Clin Obstet Gynaecol, 2016. 31: p. 30-44.

32. De Francesco, F., et al., Human Adipose Stem Cells: From Bench to Bedside. Tissue Eng Part B Rev, 2015. 21(6): p. 572-84.

33. Pittenger, M.F., et al., Multilineage potential of adult human mesenchymal stem cells. Science, 1999. 284(5411): p. 143-7.

34. Alsalameh, S., et al., Identification of mesenchymal progenitor cells in normal and osteoarthritic human articular cartilage. Arthritis Rheum, 2004. 50(5): p. 1522-32.

35. Pretzel, D., et al., Relative percentage and zonal distribution of mesenchymal progenitor cells in human osteoarthritic and normal cartilage. Arthritis Res Ther, 2011. 13(2): p. R64.

36. Hatakeyama, A., et al., Isolation and Characterization of Synovial Mesenchymal Stem Cell Derived from Hip Joints: A Comparative Analysis with a Matched Control Knee Group. Stem Cells Int, 2017. 2017: p. 9312329.

37. Cheng, M.T., et al., Isolation and characterization of multipotent stem cells from human cruciate ligaments. Cell Prolif, 2009. 42(4): p. 448-60. 
38. O'Donnell, J.M., B.M. Devitt, and M. Arora, The role of the ligamentum teres in the adult hip: redundant or relevant? A review. J Hip Preserv Surg, 2018. 5(1): p. 15-22.

39. Boeuf, S. and W. Richter, Chondrogenesis of mesenchymal stem cells: role of tissue source and inducing factors. Stem Cell Res Ther, 2010. 1(4): p. 31.

40. Segawa, Y., et al., Mesenchymal stem cells derived from synovium, meniscus, anterior cruciate ligament, and articular chondrocytes share similar gene expression profiles. J Orthop Res, 2009. 27(4): p. 435-41.

41. Baghaei, K., et al., Isolation, differentiation, and characterization of mesenchymal stem cells from human bone marrow. Gastroenterol Hepatol Bed Bench, 2017. 10(3): p. 208-213.

42. Li, X., et al., Bone Marrow- and Adipose Tissue-Derived Mesenchymal Stem Cells: Characterization, Differentiation, and Applications in Cartilage Tissue Engineering. Crit Rev Eukaryot Gene Expr, 2018. 28(4): p. 285-310.

43. Hermida-Gomez, T., et al., Quantification of cells expressing mesenchymal stem cell markers in healthy and osteoarthritic synovial membranes. J Rheumatol, 2011. 38(2): p. 339-49.

44. Djouad, F., et al., Transcriptional profiles discriminate bone marrow-derived and synovium-derived mesenchymal stem cells. Arthritis Res Ther, 2005. 7(6): p. R1304-15.

45. Johnstone, B., et al., In vitro chondrogenesis of bone marrow-derived mesenchymal progenitor cells. Exp Cell Res, 1998. 238(1): p. 265-72.

46. Jahr, H., C. Matta, and A. Mobasheri, Physicochemical and biomechanical stimuli in cell-based articular cartilage repair. Curr Rheumatol Rep, 2015. 17(3): p. 22.

47. Kisiday, J.D., et al., Dynamic compression stimulates proteoglycan synthesis by mesenchymal stem cells in the absence of chondrogenic cytokines. Tissue Eng Part A, 2009. 15(10): p. 2817-24.

48. Wagner, D.R., et al., Hydrostatic pressure enhances chondrogenic differentiation of human bone marrow stromal cells in osteochondrogenic medium. Ann Biomed Eng, 2008. 36(5): p. 813-20.

49. Elahi, K.C., et al., Human Mesenchymal Stromal Cells from Different Sources Diverge in Their Expression of Cell Surface Proteins and Display Distinct Differentiation Patterns. Stem Cells Int, 2016. 2016: p. 5646384.

50. Sheng, G., The developmental basis of mesenchymal stem/stromal cells (MSCs). BMC Dev Biol, 2015. 15: p. 44.

51. Murray, I.R. and B. Peault, Q\&A: Mesenchymal stem cells - where do they come from and is it important? BMC Biol, 2015. 13: p. 99.

52. Samsonraj, R.M., et al., Concise Review: Multifaceted Characterization of Human Mesenchymal Stem Cells for Use in Regenerative Medicine. Stem Cells Transl Med, 2017. 6(12): p. 2173-2185.

\section{Tables}

Table 1: Primer details for semiquantitative RT-PCR 


\begin{tabular}{|c|c|c|c|c|c|}
\hline gene & primer sequences $\left(5^{\prime}-3^{\prime}\right)$ & $\begin{array}{l}\text { annealing } \\
\text { temperature } \\
\left({ }^{\circ} \mathrm{C}\right)\end{array}$ & $\begin{array}{l}\text { product size } \\
\text { (base pairs) }\end{array}$ & cycles & $\mathrm{MgCl}_{2}$ \\
\hline \multicolumn{6}{|c|}{ housekeeping gene for internal control } \\
\hline EEF1 $\alpha$ & $\begin{array}{l}\text { Sense: AGGTGATTATCCTGAACCATCC Antisense: } \\
\text { AAAGGTGGATAGTCTGAGAAGC }\end{array}$ & 54.0 & 234 & 21 & $1 \mathrm{x}$ \\
\hline \multicolumn{6}{|c|}{ adipogenic marker genes } \\
\hline LPL & $\begin{array}{l}\text { Sense: } \\
\text { GAGATTTCTCTGTATGGCACC } \\
\text { Antisense: } \\
\text { CTGCAAATGAGACACTTTCTC }\end{array}$ & 51.0 & 239 & 30 & $1 \mathrm{x}$ \\
\hline PPARY & $\begin{array}{l}\text { Sense: } \\
\text { GCTGTTATGGGTGAAACTCTG } \\
\text { Antisense: } \\
\text { ATAAGGTGGAGATGCAGGCTC }\end{array}$ & 61.0 & 297 & 35 & $1 \mathrm{x}$ \\
\hline \multicolumn{6}{|c|}{ osteogenic marker genes } \\
\hline Col I & $\begin{array}{l}\text { Sense: } \\
\text { GGACACAATGGATTGCAAGG } \\
\text { Antisense: } \\
\text { TAACCACTGCTCCACTCTGG }\end{array}$ & 55.0 & 461 & 22 & $2 \mathrm{x}$ \\
\hline Col X & $\begin{array}{l}\text { Sense: } \\
\text { CCCTTTTTGCTGCTAGTATCC } \\
\text { Antisense: } \\
\text { CTGTTGTCCAGGTTTTCCTGGCAC }\end{array}$ & 54.0 & 468 & 40 & $1 \mathrm{x}$ \\
\hline ALP & $\begin{array}{l}\text { Sense: } \\
\text { TGGAGCTTCAGAAGCTCAACACCA } \\
\text { Antisense: } \\
\text { ATCTCGTTGTCTGAGTACCAGTCC }\end{array}$ & 51.0 & 454 & 33 & $1 \mathrm{x}$ \\
\hline $\mathrm{OC}$ & $\begin{array}{l}\text { Sense: } \\
\text { ATGAGAGCССТCACAСТССТC }\end{array}$ & 62.0 & 293 & 35 & $2 \mathrm{x}$ \\
\hline
\end{tabular}




\begin{tabular}{|c|c|c|c|c|c|}
\hline & $\begin{array}{l}\text { Antisense: } \\
\text { GCCGTAGAAGCGCCGATAGGC }\end{array}$ & & & & \\
\hline \multicolumn{5}{|c|}{ chondrogenic marker genes } & \\
\hline AGG & $\begin{array}{l}\text { Sense: } \\
\text { GCCTTGAGCAGTTCACCTTC } \\
\text { Antisense: } \\
\text { CTCTTCTACGGGGACAGCAG }\end{array}$ & 54.0 & 400 & 35 & $1 \mathrm{x}$ \\
\hline Col II & $\begin{array}{l}\text { Sense: } \\
\text { TTTCCCAGGTCAAGATGGTC } \\
\text { Antisense: } \\
\text { CTTCAGCACCTGTCCACCA }\end{array}$ & 51.0 & 155 & 31 & $1 \mathrm{x}$ \\
\hline Sox-9 & $\begin{array}{l}\text { Sense: } \\
\text { ATCTGAAGAAGGAGAGCGAG } \\
\text { Antisense: } \\
\text { TCAGAAGTCTCCAGAGCTTG }\end{array}$ & 60.0 & 263 & 31 & $1 \mathrm{x}$ \\
\hline
\end{tabular}

EEF 1a, Elongation factor 1a; LPL, lipoproteinlipase; PPARy, peroxisome proliferator-activated receptor $\mathrm{Y}$; Col I, collagen type I; Col X, collagen type X; ALP, alkaline phosphatase; OC, osteocalcine; AGG, aggrecane; Col II, collagen type II; Sox-9, sex-determining region Y-box 9;

Table 2: Percental distribution of cells positive for examined surface antigens.

\begin{tabular}{|c|c|c|c|c|}
\hline & bone marrow & cartilage & $\mathrm{LCF}$ & capsule \\
\hline $\mathrm{CD}{ }^{+} / \mathrm{CD} 105^{+}$ & $99.8 \%$ & $99.6 \%$ & $99.8 \%$ & $99.8 \%$ \\
\hline $\mathrm{CD}_{4} 4^{+} / \mathrm{CD} 3^{+}$ & $79.7 \%$ & $75.8 \%$ & $53.1 \%$ & $70.4 \%$ \\
\hline $\mathrm{CD}^{+} 0^{+}$ & $99.9 \%$ & $99.9 \%$ & $99.8 \%$ & $99.8 \%$ \\
\hline CD105+ & $99.8 \%$ & $99.6 \%$ & $99.8 \%$ & $99.8 \%$ \\
\hline $\mathrm{CD}_{4} 4^{+}$ & $99.8 \%$ & $99.4 \%$ & $98.7 \%$ & $99.5 \%$ \\
\hline $\mathrm{CD}^{+}{ }^{+}$ & $79.7 \%$ & $76.0 \%$ & $53.5 \%$ & $70.6 \%$ \\
\hline
\end{tabular}

Percentages of isolated cells from bone marrrow, hyaline cartilage, LCF and the joint capsule that (co)expressed the surface antigens $\mathrm{CD} 44^{+}, \mathrm{CD} 73^{+}, \mathrm{CD} 90^{+}$or $\mathrm{CD} 105^{+}$as measured by fluorescenceactivated cell sorting. $\mathrm{CD}$, cluster of differentiation; ${ }^{+}$, positve expression; 


\section{Figures}

\section{Hematoxylin-Eosin}
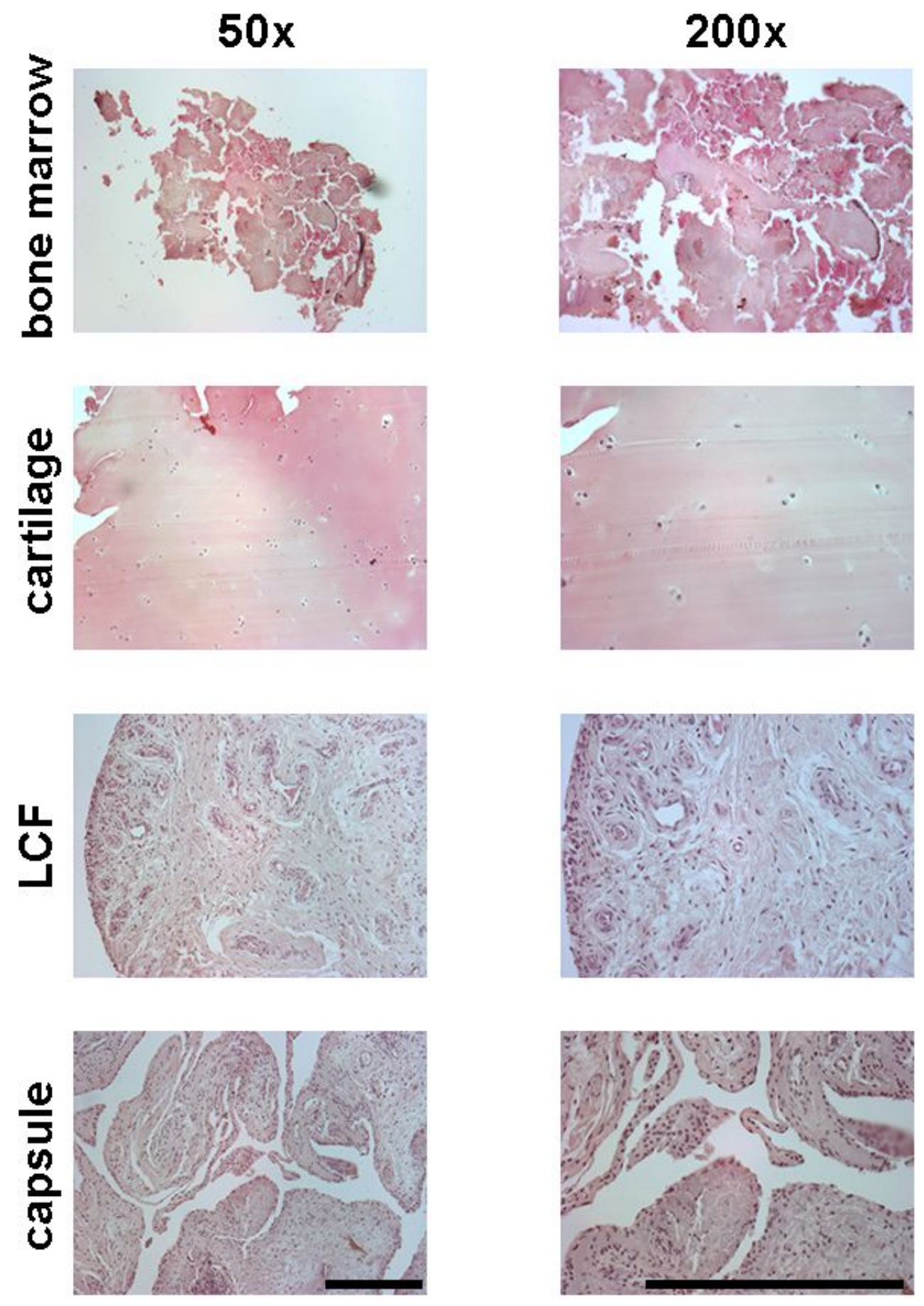

Figure 1

H\&E stainings of native tissue samples derived from all four examined segments of the hip joint. Minced tissue samples from bone marrow, arthritic hyaline cartilage, the LCF and the joint capsule were fixed in $4 \%$ formaldehyde and stained with H\&E to examine tissue sturcture and cell morphology. The images 
were captured at low $(50 x$; black bar $=300 \mu \mathrm{m})$ and high $(200 x$; black bar $=300 \mu \mathrm{m})$ magnification. LCF, ligamentum capitits femoris.

\section{FACS analysis of specific surface antigens}
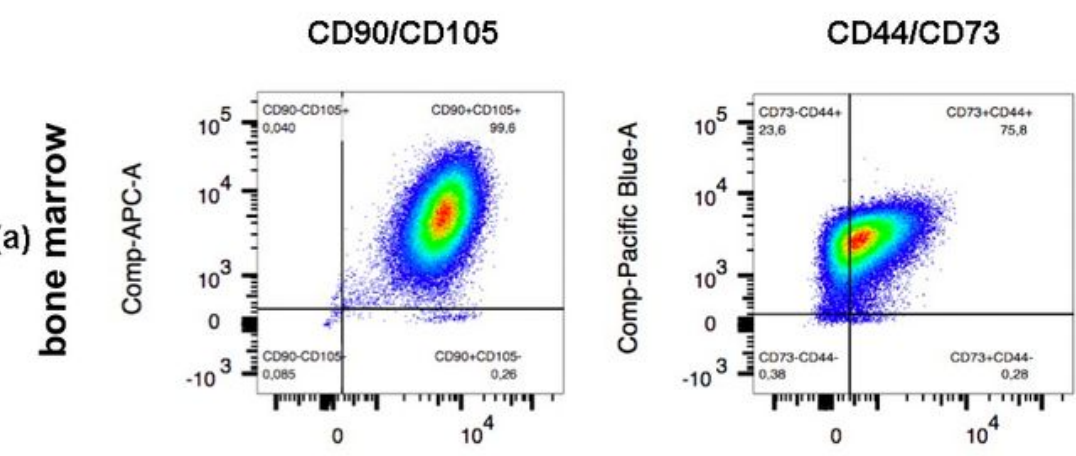

Comp-FITC-A

(b)
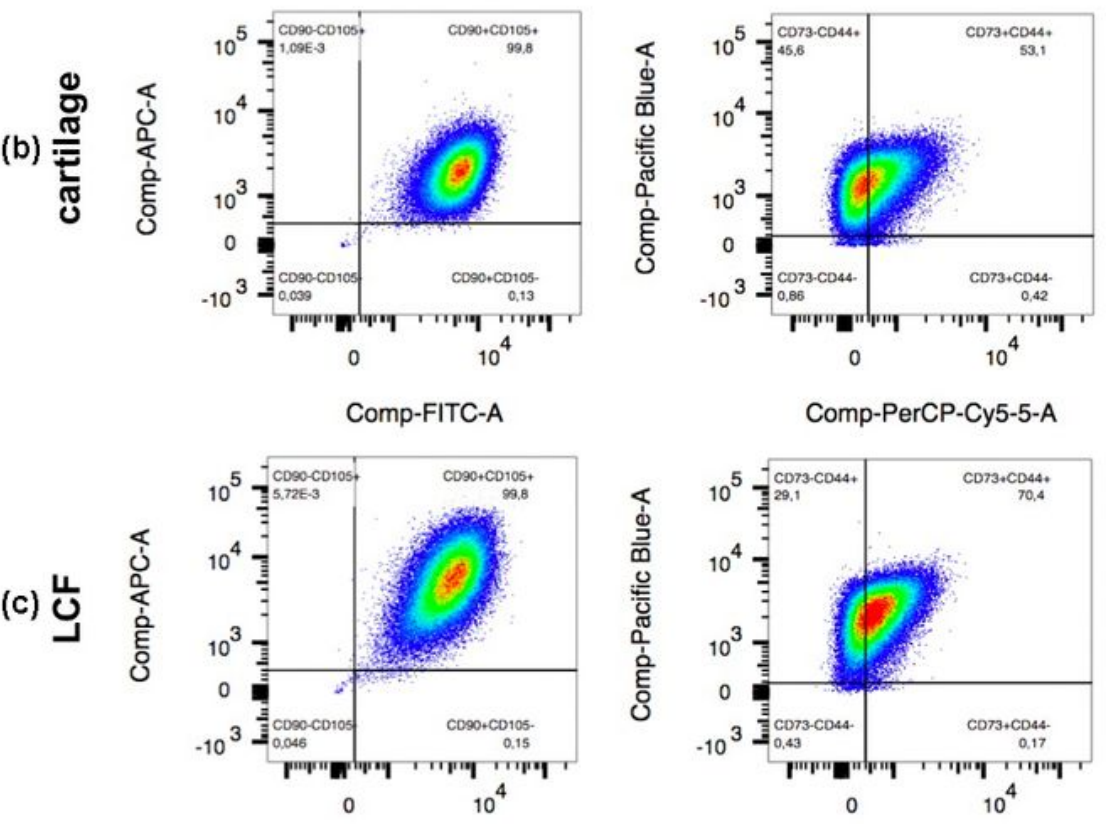

Comp-FITC-A

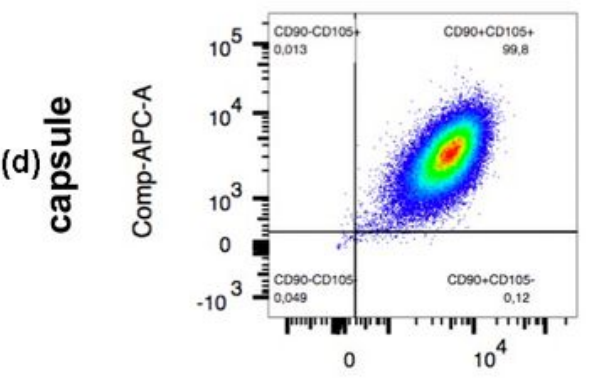

Comp-FITC-A

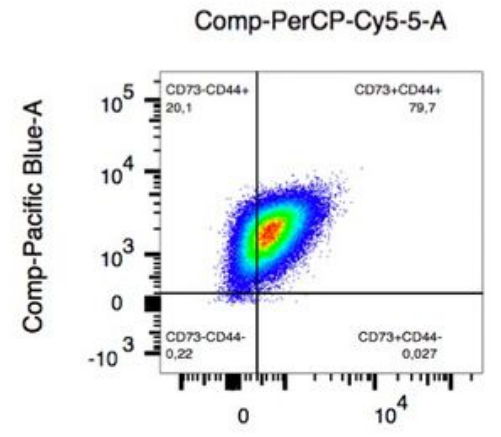

Comp-PerCP-Cy5-5-A

Figure 2

Fluorescence-acitvated cell sorting (FACS) analysis for the expression of surface antigens on all isolated cells. A minimum amount of $5 \times 105$ cells from bone marrow (a), hyaline cartilage (b), the LCF (c) and the joint capsule (d) were examined for the (co)expression of surface antigens CD44, CD73 (CD44/CD73), 
CD90 and CD105 (CD90/CD105). The results were pictured using the FLowJo 10.5.3 Software by FlowJo LLC. While almost all cells ( $\geq 95 \%$ ) were positive for the surface markers CD44, CD 90 and CD105 the percentage of CD73+ cells ranged from about $53-80 \%$ depending on the donor tissue. No significant differences were found between the cells from varying origins. The exact results are pictured in Table 2 . $C D$, cluster of differentiation. LCF, ligamentum capitits femoris.

Adipogenesis

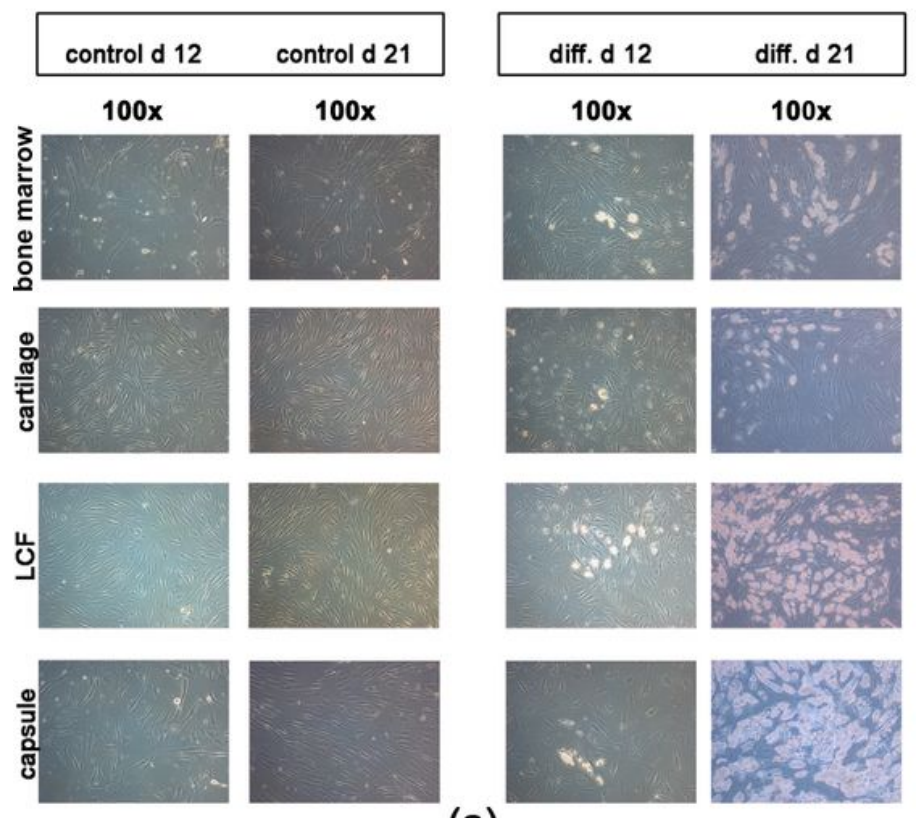

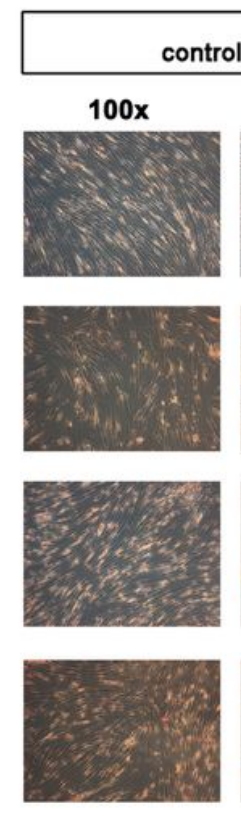

(a)
Oil RedO

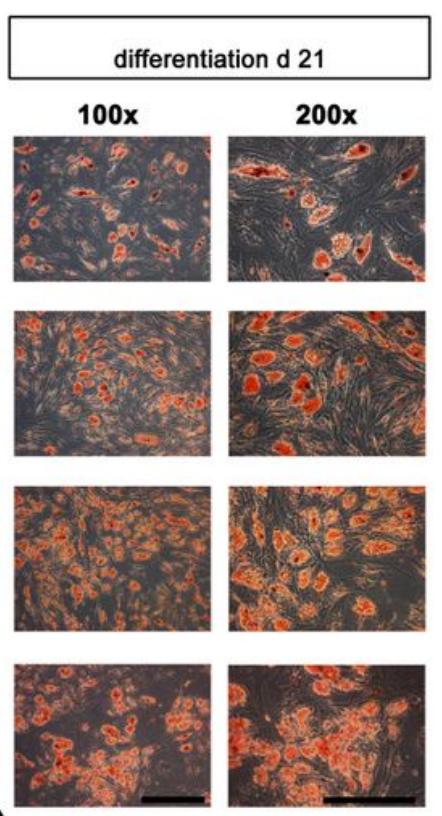

(b)

\section{Figure 3}

Assay of adipogenesis in mesenchymal progenitor cells after 21 days in monolayer cell culture. For inducing adipogenesis monolayer cultures containing mesenchymal progenitor cells from bone marrow, hyaline cartilage, LCF and the joint capsule were incubated with adipogenic differentiation medium for 21 days. Controls were maintained in cell culture medium. Both native, unstained tissue samples (a) and Oil RedO stainings (b) from control and differentiatied samples were compared. In contrast to controls the formation of lipid droplets increased during day 12 to day 21 of adipogenesis (a) and all differentiated cultures stained positive for Oil Red $\mathrm{O}$ at the end of the differentiation period (b). Representative samples were captured at low $(100 x$; black bar $=200 \mu \mathrm{m})$ and high $(200 x$; black bar $=150 \mu \mathrm{m})$ magnification. $\mathrm{d}$, days; diff., differentiation; LCF, ligamentum capitits femoris.

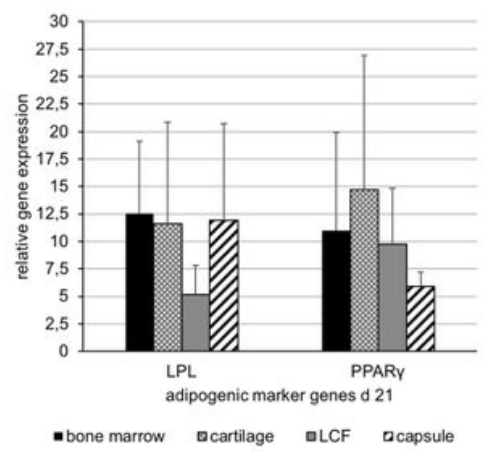

(a)

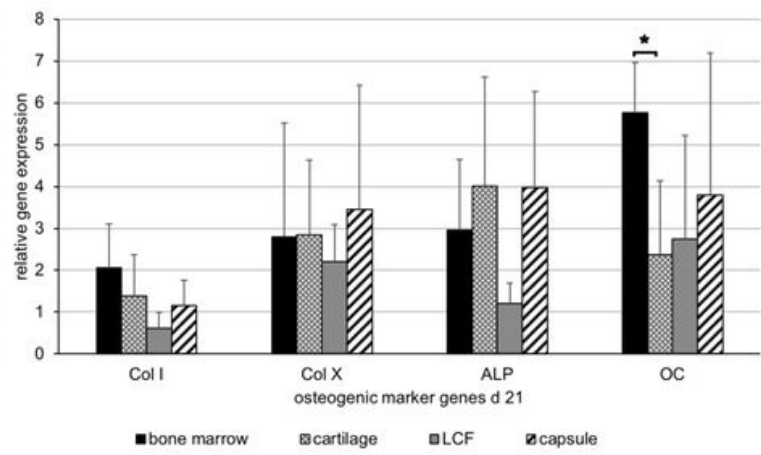

(b)

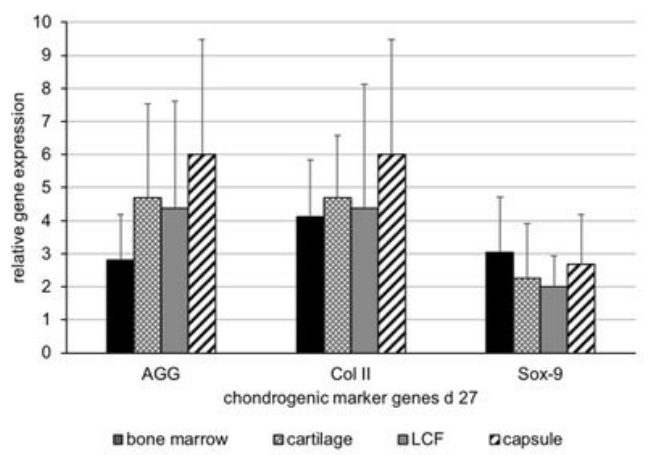

(c) 


\section{Figure 4}

Mean changes in the expression of adipogenic, osteogenic and chondrogenic marker genes \pm standard deviation as measured by semiquantitative RT-PCR in mesenchymal progenitor cells at the end of the respective differentiation period. Mesenchymal progenitor cells derived from bone marrow, hyaline cartilage, LCF and the joint capsule were incubated with adipogenic (21 d), osteogenic (21 d) and chondrogenic (27 d) differentiation medium. The mean changes in the relative expression of the adipogenic (a) marker genes - lipoproteinlipase (LPL) and peroxisome proliferator-activated receptor $Y$ (PPARY) - the osteogenic (b) marker genes - collagen type I (Col I), collagen type X (Col X), alkaline phosphatase (ALP) and osteocalcin (OC) - as well as the chondrogenic (c) marker genes - (AGG), collagen type II (Col II) and sex-determining region Y-box 9 (Sox-9) - are pictured, respectively. Elongation factor 1a (EEF 1a) was used as the housekeeping gene and for internal controls. Primer details are illustrated in Table 1. d, days; LCF, ligamentum capitits femoris.

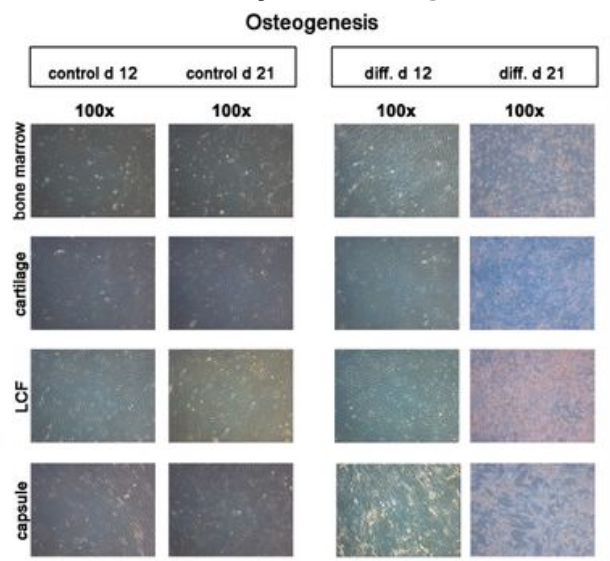

(a)

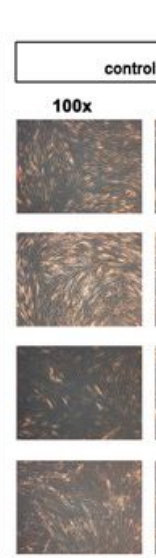

Alizarin Red S

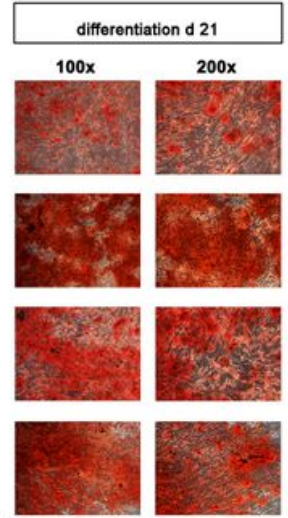

(b)

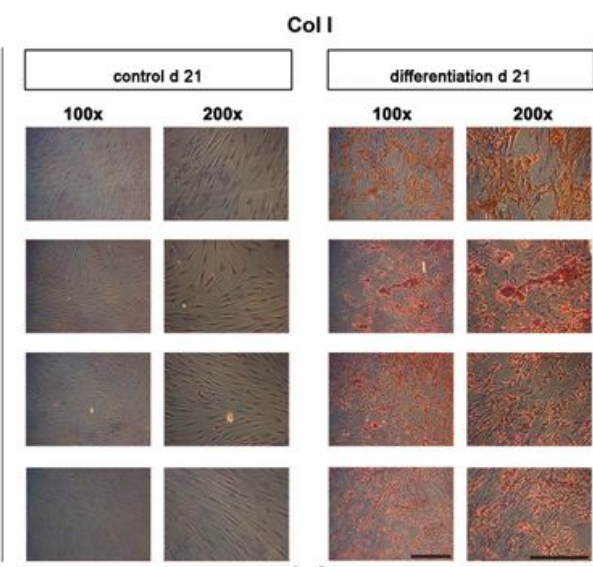

(c)

\section{Figure 5}

Histological and immunohistochemicasl assay of osteogenesis in mesenchymal progenitor cells after 21 days in monolayer cell culture. For inducing osteogenesis monolayer cultures containing mesenchymal progenitor cells from bone marrow, hyaline cartilage, LCF and the joint capsule were incubated with osteogenic differentiation medium for 21 days. Contols were maintained in cell culture medium. Native, unstained tissue samples (a), Alizarin Red S stainings (b) for detection of extracellular calcium deposits and immunohistochemical stainings of collagen type I (Col l; c) from control and differentiatied samples were compared. From day 12 to day 21 dense deposits formed in differentiated monolayers and Alizarin Red S (a) as well as immunhistochemical stainings of Col I (c) were positive in all differentiated cell cultures in contrast to controls. Representative samples were captured at low (100x; black bar = $200 \mu \mathrm{m})$ and high $(200 x$; black bar $=150 \mu \mathrm{m})$ magnification. Col I, collagen type l; d, days; diff., differentiation; LCF, ligamentum capitits femoris. 


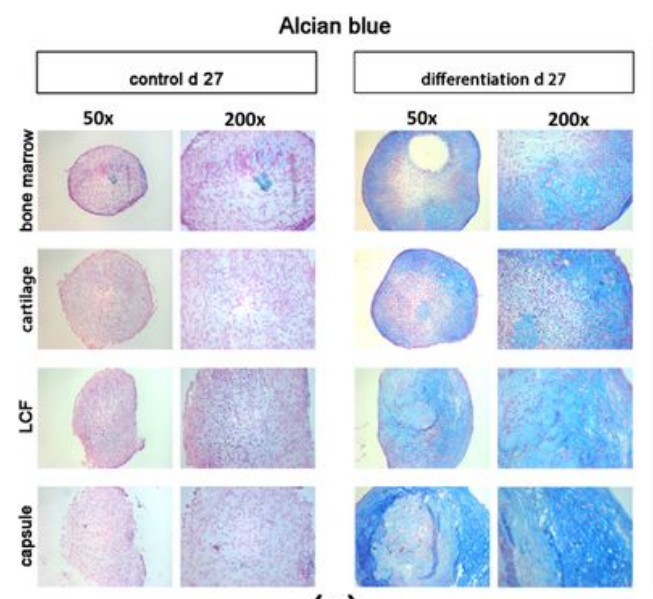

(a)

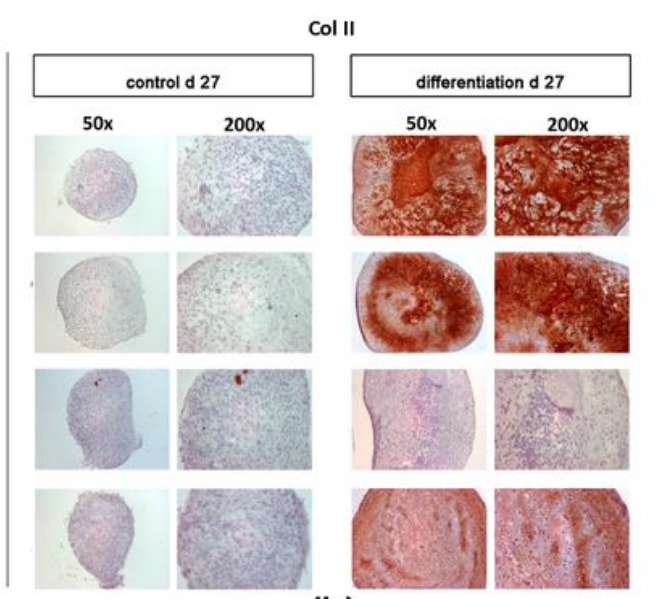

(b)

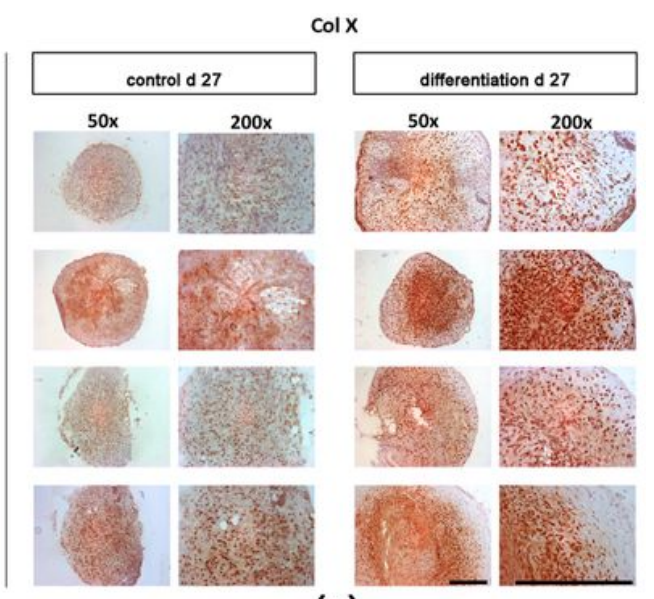

(c)

\section{Figure 6}

Histological and immunohistochemical analysis of chondrogenesis in mesenchymal progenitor cells after $27 \mathrm{~d}$ of pellet culture in presence of transforming growth factor- $\beta 1$. For inducing chondrogenesis pellets containing mesenchymal progenitor cells from bone marrow, hyaline cartilage, LCF and the joint capsule were incubated with chondrogenic differentiation medium for 27 days. Contols were maintained in cell culture medium. After 27 days alcian blue staining (a) was performed for the detection of proteoglycans. While the controls remained negative all differentiated pellets showed positive alcian blue stainings. Immunohistochemical stainings of collagen type II (Col II; b) and collagen type X (Col X; right panel) were performed on pellet sections containing mesenchymal progenitor cells from bone marrow, hyaline cartilage (b), the LCF (c) and the joint capsule (d) after incubation in chondrogenic differentiation medium for 27 days. Controls were maintained in cell culture medium for the same duration of time (left panel). Positive staining for collagen type II (Col II; b) appeared red. Col II was detected in all differentiated pellet sections except from LCF $(b, L C F)$, while moderate collagen type $X(C o l X ; c)$ stainings were shown in all differntiated pellet sections and their controls after 27 days (c). Representative samples were captured at low $(50 x$; black bar $=300 \mu \mathrm{m})$ and high $(200 x$; black bar $=300 \mu \mathrm{m})$ magnification. Col II, collagen type I; Col $X$, collagen type $X$; d, days; diff., differentiation; LCF, ligamentum capitits femoris. 